\title{
Marzena Karwowska
}

Uniwersytet Łódzki

\section{Mit we współczesnych badaniach literackich}

Inicjatorem współczesnych badań nad mitem w Europie jest francuski filozof i antropolog wyobraźni Gilbert Durand, który ideę mitokrytyki wyłożył i rozwinął w publikacji z 1979 roku Figures mythiques et visages de l'œuvre. De la mythocritique à la mythanalyse $e^{1}$. Zapoczątkowany przez Duranda nurt antropologicznych badań nad mitem jako strukturą wyobraźni w literaturoznawstwie musiał zmierzyć się z przeszkodą, jaką był dystans środowisk naukowych do fundamentalnej dla tych badań Eliadowskiej koncepcji mitu i symbolu. W ujęciu Mircei Eliadego mit i symbol to struktury ponadhistoryczne, wywodzące się z tradycji oralnej o charakterze sakralnym, literaturoznawstwo zaś zwykło się zajmować tekstami pisanymi, profanicznymi, wpisanymi w historię ${ }^{2}$. Ten hiatus między logosem i mitem zniosły już w antropologii strukturalnej badania Claude’a Lévi-Straussa, który zaproponował rodzaj powszechnej gramatyki mitu i wpisanego w mit symbolu, traktując je jako formy uniwersalne, transcendujące czas i różnice kulturowe ${ }^{3}$, co zostało następnie zaanektowane przez badaczy z kręgu postdurandowskiego. Sully Bernadie definiuje antropologiczne badania nad wyobraźnią jako badania nad sekretną architekturą ludzkiego świata wyobrażeń, które powracają w historii kultury w sposób

${ }^{1}$ Do uprzywilejowania mitu w naukach humanistycznych, których zwieńczeniem jest współczesna mitokrytyka, przyczyniły się wcześniejsze prace takich badaczy, jak: E. Cassirer, C.G. Jung, M. Eliade, C. Lévi-Strauss i G. Bachelard.

${ }^{2}$ Zwraca na to uwagę Véronique Gély w artykule Mythes et littérature. Bilan critique, [w:] Mythes et littérature, red. S. Parizet, Lucie éditions pour la SFLGC, Paris 2008, s. 179-195.

${ }^{3}$ Por. C. Lévi-Strauss, Antropologia strukturalna, przeł. K. Pomian, Warszawa 1970. 
periodyczny ${ }^{4}$. Socjolog wyobraźni Jean Duvignaud dowodzi, że w historii rozwoju społeczeństw daje się zaobserwować silną obecność ekspresji świata wyobrażeń za pomocą figuratywnych reprezentacji. Zjawisko to badacz odczytuje jako przejaw laicyzacji kultury społeczeństw, które obrazem (posiadającym korzenie mityczne, a więc sakralne) próbują zapełnić obszary przez kulturę zdesakralizowane ${ }^{5}$. Niektórzy literaturoznawcy reprezentujący postdurandowski nurt badań, np. Pierre Albouy ${ }^{6}$, wprowadzają w tym celu wyraźne rozróżnienie pomiędzy mitem etno-religijnym i mitem literackim. André Siganos, zwolennik Durandowskiej mitokrytyki, twierdzi natomiast, że każdy mit etno-religijny może stać się mitem literackim, jeśli zacznie funkcjonować w tekście literackim ${ }^{7}$. Pierre Brunel użyteczność teorii Duranda do badań literackich uzasadnia tym, że elementy mityczny i symboliczny są strukturami dominującymi we wszystkich utworach literackich, w procesie rozwoju literatury nastąpił bowiem proces przejścia od literatury mitologicznej (przechowującej obrazy o korzeniach mitycznych) do literatury kreującej mity ${ }^{8}$. Frédéric Monneyron i Joël Thomas stawiają wreszcie tezę najbardziej radykalną - cała literatura to nowoczesna forma mitu9.

Najważniejszym terenem badań nad wyobraźnią w duchu Durandowskim pozostaje do dziś Francja ${ }^{10}$. Tutaj powstał najstarszy

${ }^{4}$ Por. S. Bernadie, L'Espace imaginaire, „Recherches et Travaux” 1977, nr 15 (L'Imaginaire), s. 108.

5 Por. J. Duvignaud, Spectacle et société, Denoël-Gonthier, Paris 1970.

${ }^{6}$ Por.. P. Albouy, Quelques gloses sur la notion de mythe littéraire, [w:] Mythographies, José Corti, Paris 1976, s. 267-272.

7 A. Siganos, Définitions du mythe, [w:] Questions de mythocritique. Dictionnaire, red. D. Chauvin, A. Siganos, Ph. Walter, Imago, Paris 2005, s. 85-100.

${ }^{8}$ Mythes et littérature, red. P. Brunel, Presses de l'Université de Paris-Sorbonne, Paris 1994, s. 10.

${ }^{9}$ Szerzej na ten temat por. F. Monneyron, J. Thomas, Mythes et littérature, PUF, Paris 2002.

10 Pierre Brunel, propagator postdurandowskich badań nad literaturą na Uniwersytecie Paris IV Sorbonne, w 1983 roku wyraża obawę, że ze względu na budzą- 
w świecie (założony w 1966 roku) Ośrodek Badań nad Wyobraźnią (CRI - Centre de Recherche sur l'Imaginaire) na Uniwersytecie Stendhala w Grenoble, prowadzący interdyscyplinarne badania nad symbolem, mitem i archetypem. Obszar zainteresowań badawczych ośrodka z Grenoble obrazuje najpełniej jego wyjątkowo prężna działalność wydawnicza. CRI wydaje czasopismo „IRIS”11 propagujące postdurandowski nurt badań, publikuje też cyklicznie serię wydawniczą pod nazwą „Atelier de l'Imaginaire”. Na Uniwersytecie Paris IV Sorbonne został powołany do życia ośrodek badań nad wyobraźnią utrzymanych w duchu Durandowskim, w którym z inicjatywy Danièle Chauvin ${ }^{12}$ i Pierre'a Brunela podejmowane były liczne przedsięwzięcia naukowe mające na celu jednoczenie międzynarodowego środowiska badaczy wyobraźni ${ }^{13}$ oraz

cą tak duże kontrowersje eliadowsko-durandowską koncepcję mitu i symbolu badania te mogą zostać ograniczone terytorialnie wyłącznie do Francji, co potwierdza w roku 1992, kiedy ciągle jeszcze propagowana szeroko przez „Szkołę z Grenoble” postawa badawcza wśród komparatystów poza granicami Francji jest rzadkością, por. P. Brunel, L'Etude des mythes en littérature comparée, [w:] idem, Mythocritique. Théorie et parcours, PUF, Paris 1992, s. 27.

${ }^{11}$ Najnowszy interdyscyplinarny numer czasopisma skupiony jest wokół haseł: „umysł wyobrażający - umysł wyobrażony”, por. Les imaginaires du cerveau, red. M.A. Cathiard, P. Pajon, „Iris” 2015, nr 35. Tom zadedykowany został Philippowi Walterowi, który przez ostatnie piętnaście lat kierował Ośrodkiem Badań nad Wyobraźnią w Grenoble i prowadził badania nad światem wyobrażeń średniowiecznej Europy, por. Ph. Walter, Perceval, le pêcheur et le Graal, Imago, Paris 2004; idem, La Mythologie chrétienne, fêtes, rites et mythes du Moyen Age, Imago, Paris 2003; idem, Arthur, l'ours et le roi, Imago, Paris 2002; idem, Merlin ou le savoir du monde, Imago, Paris 2000.

${ }^{12}$ Danièle Chauvin była w latach 1989-1998 dyrektorem Ośrodka Badań nad Wyobraźnią (CRI) na Uniwersytecie Stendhala w Grenoble.

${ }^{13}$ W marcu 2004 roku Uniwersytet Paris IV Sorbonne zorganizował międzynarodową konferencję poświęconą mitycznym figurom Ziemi, zatytułowaną Figures de la Terre dans la littérature et l'art européens. Materiały z tej konferencji, której współorganizatorem był Ośrodek Kultury Polskiej na Sorbonie, ukazały się w publikacji: Les Représentations de la Terre dans la littérature et l'art européens. Imaginaire et Idéologie. Actes du colloque des 18-19-20 mars 2004 en Sorbonne, red. D. Chauvin, D. Knysz-Tomaszewska, „Les Nouveaux Cahiers Franco-Polonais” $2005, \mathrm{nr} 4$. 
działania edytorskie (seria wydawnicza Figury i Mity, publikowana przez Wydawnictwo Rocher $\left.{ }^{14}\right)$. Badania z zakresu mitopoetyki ${ }^{15}$ prowadzi na Uniwersytecie Paris X grupa naukowców pod kierunkiem Véronique Gély ${ }^{16}$ - wskazują one na ciekawe tendencje zaznaczające się we współczesnych analizach postdurandowskich, polegające na znacznym rozszerzeniu obszaru zainteresowań. I tak Sylvie Parizet nie tylko faworyzuje mity biblijne (podobnie jak wielu innych hermeneutów, np. Danièle Chauvin ${ }^{17}$ ), ale śledzi również związki między mitem i gatunkami literackimi ${ }^{18}$; Véronique Gély bada zależności mitu i alegorii ${ }^{19}$, mitu i monologu oraz mitu i dialo$\mathrm{gu}^{20}$; Sylvie Ballestra-Puech zajmuje się paralelami między strukturami mitycznymi i metaforą. W ostatnich latach interdyscyplinarne badania nad mitem i symbolem, wywodzące się z tradycji durandowskiej, zaczynają być coraz częściej obecne w działaniach naukowych poza granicami Francji: na Uniwersytecie w Brukseli (projekt Metody lektury mitu, koordynator Lambroso Couloubaritsis ${ }^{21}$,,

${ }^{14} \mathrm{~W}$ serii tej ukazały się między innymi książki: Æ. Bastian, P. Brunel, Sisiphe et son rocher, Éditions du Rocher, Paris 2004; F. Toudoire-Surlapierre, Hamlet, l'ombre et la mémoire, Éditions du Rocher, Paris, 2004; S. Détoc, La Gorgone Méduse, Éditions du Rocher, Paris 2006.

15 Termin „mitopoetyka” zaproponował Pierre Brunel, który postulował odejście od klasycznej trychotomicznej teorii genologicznej i wprowadzenie mitu jako czwartego rodzaju literackiego - najstarszego, fundamentalnego, z którego wyłoniły się wszystkie pozostałe, P. Brunel, Mythopoétique des genres, PUF, Paris 2003, s. 182-183.

${ }^{16}$ Le Mythe en littérature. Mélanges offerts à Pierre Brunel, red. C. Dumoulié, Y. Chevrel, PUF, Paris 2000.

17 D. Chauvin, La Bible, images, mythes et traditions, Albin Michel, Paris 1994.

${ }^{18}$ Lectures politiques des mythes littéraires au $\mathrm{XX}^{e}$ siècle, red. S. Parizet, Presses Universitaires de Paris Ouest, Paris 2009.

${ }^{19}$ V. Gély, L'Invention d'un mythe: Psyché. Allégorie et fiction, du siècle de Platon au temps de La Fontaine, Champion, Paris 2006.

${ }^{20}$ Eadem, La Nostalgie du moi. Écho dans la litérature européenne, PUF, Paris 2000.

${ }^{21}$ Belgijscy naukowcy wyniki swoich prac badawczych opublikowali w tomach: S. Klimis, Le Statut du mythe dans la poétique d'Aristote. Les fondements philosophique de la tragédie, Ousia, Bruxelles 1997; Antigone et la résistance civile, red. L. Couloubaritsis, J.F. Ost, Ousia, Bruxelles 2004. 
w Lozannie (Ute Heidmann ${ }^{22}$ ).W 2006 roku w Moskwie odbyła się konferencja Poetyka mitu dzisiaj poświęcona dorobkowi Eleazara Mieletinskiego.

W badaniach antropologiczno-mitokrytycznych przyjmuje się za Durandem definicję mitu jako dynamicznego systemu symboli (figur mitycznych), archetypów, obrazów i schematów, które układają się w narracje inkorporowane trwale w kulturę. Dzięki literackiej palingenezie narracji mitycznych mit archaiczny ożywiany jest każdorazowo poprzez dynamizm opowieści, a mit uniwersalny staje się mitem osobistym, indywidualnym, jako „najstarsza werbalizacja aspektów ponadindywidualnych i zbiorowych rzeczywistości przeżytej”23. Jean-Jacques Wunenburger wprowadza pojęcie wyobraźni mito-poïetycznej, definiowanej jako szczególny rodzaj wyobraźni, w której mit uaktywnia wyobraźnię fabularną, generującą (na kanwie opowieści mitycznych) historie fikcyjne ${ }^{24}$. Wunenburger utożsamia aktywność mito-poïetyczną wyobraźni $\mathrm{z}$ aktywnością symboliczną ${ }^{25}$, poszukuje istoty reprezentacji symbolicznych wpisanych w zależność Mythos-Logos, mitogenezę postrzegając jako proces noetyczny. Jest też twórcą koncepcji Cogito mitofanii, według której Cogito Marzyciela ('ja myślę’) z podmiotu staje się bytem przedmiotowym Cogitor ('jestem myślany’²6.

${ }^{22}$ U. Heidmann (red.), Poétique comparée des mythes. De l'antiquité á la modernité, Payot, Lausanne 2004.

${ }^{23}$ A. Deremetz, Petite histoire des définitions du mythe. Le mythe: un concept ou un nom?, [w:] Mythe et création, red. P. Cazier, Presses Universitaires de Lille, Lille 1994, s. 22. Na zjawisko personalizacji mitu uniwersalnego w pismach antropologicznych Gastona Bachelarda zwraca uwagę Jean-Claude Margolin, por. J.-C. Margolin, Bachelard, Seuil, Paris 1974, s. 98-99.

${ }^{24}$ J.J. Wunenburger, Principes d'une imagination mytho-poïetique, [w:] Mythe et création, op. cit., s. 36. Termin ,poïetyczny” zapożyczony został od Arystotelesa, dla którego był synonimem działalności wytwórczej człowieka. W badaniach nad wyobraźnią termin ten oznacza produktywność wyobraźni, jej potencjalność kreacyjną, dzięki której możliwe są nowe kreacje.

${ }^{25}$ Ibidem, s. 40.

${ }^{26}$ Ibidem, s. 45. 
Simone Vierne ${ }^{27}$ na podstawie wieloletnich badań mitokrytycznych formułuje wniosek, że w dziełach literackich, przechowujących fundamentalne obrazy archetypowe, można odnaleźć wspólny rdzeń o charakterze esencjonalnym, jednak dynamizm wyobraźni twórczej sprawia, że obrazy te osiągają odmienną realizację artystyczną w dziełach konkretnych twórców, w konkretnym kontekście historycznym czy gatunku literackim ${ }^{28}$.

Gilbert Durand, autor wznawianej kilkakrotnie i tłumaczonej na wiele języków pracy z 1960 roku Les structures anthropologiques de l'imaginaire ${ }^{29}$, w przedmowie do jedenastego wydania tej książki z roku 1992 (ukazało się nakładem paryskiego wydawnictwa Dunod) pisze, że celowość podjętych przez niego trzydzieści lat wcześniej badań nad wyobraźnią została zweryfikowana pozytywnie przez czas. O niesłabnącym zainteresowaniu badaczy teorią antropologicznych struktur wyobraźni i mitokrytyką świadczą zabiegi domów wydawniczych zwieńczone dziesięcioma wcześniejszymi edycjami Les structures anthropologiques de l'imaginaire

${ }^{27}$ Simone Vierne, wieloletnia dyrektor założonego przez Gilberta Duranda Centre de Recherche sur l'Imaginaire w Grenoble, prowadziła badania nad wyobraźnią Juliusza Verne'a i George Sand.

${ }^{28} \mathrm{~S}$. Vierne, Rite, roman, initiation, Persses Universitaires de Grenoble, Grenoble 2000, s. 159.

${ }^{29}$ Durandowski termin imaginaire jest $\mathrm{w}$ polskojęzycznych publikacjach naukowych tłumaczony jako: 'wyobraźnia' (por. M. Dybizbański, W. Szturc, Mitoznawstwo porównawcze, Kraków 2006), 'wyobraźniowość' (por. Intertekstualność i wyobraźniowość, red. B. Sosień, Kraków 2003), 'antropologia wyobraźni twórczej' (por. M. Karwowska, Prapamięć uśpiona. Świat wyobrażeń Bolesława Leśmiana, Warszawa 2008) lub, zgodnie ze źródłosłowem francuskim, jako 'wyobrażenie'. Tytuł książki Duranda Les structures anthropologiques de l'imaginaire na język polski tłumaczony bywa dwojako: Antropologiczne struktury świata wyobrażeń (por. Potęga świata wyobrażeń, czyli archetypologia według Gilberta Duranda, red. K. Falicka, Lublin 2002) lub Antropologiczne struktury wyobraźni (por. S. Jasionowicz, Roland Barthes - Gilbert Durand, wizje pluralizmu kultury, Kraków 1999). W niniejszym rozdziale zastosowany zostanie termin ,antropologia wyobraźni twórczej”, jako że fundament koncepcji antropologicznych Duranda stanowi hermeneutyka figur wyobrażeniowych skonkretyzowanych w tekstach kultury. 
we Francji, tłumaczenia książki na języki obce (hiszpański, włoski, rumuński, angielski) oraz powstanie prawie pięćdziesięciu ośrodków badań nad wyobraźnią na całym świecie, rozwijających twórczo Durandowską metodologię (w 1991 roku w Cerisy-la-Salle odbyła się międzynarodowa konferencja naukowa poświęcona wyobraźni, w której wzięli udział przedstawiciele 47 Centrów Badań nad Wyobraźnią, reprezentujący piętnaście narodowości i pięć kontynentó $\mathrm{w}^{30}$ ).

Dynamicznie rozwijające się we współczesnej światowej nauce Durandowskie i postdurandowskie badania nad wyobraźnią twórczą weszły do historii humanistyki pod nazwą Nowej Antropologii lub Postbachelardyzmu ${ }^{31}$. Elementem porządkującym figury mityczne (wyobrażeniowe) jest w Durandowskiej antropologii wyobraźni zasada konwergencji ${ }^{32}$, dzięki której można odnaleźć „homologi semantyczne"33 i zaobserwować w tekstach pochodzących z różnych kręgów kulturowych izomorfizm obrazów, tworzących ponadkulturową ścieżkę antropologiczną ${ }^{34}$. Cechą antropologicznych struktur wyobraźni jest zdolność do replikacji, ulegają one metamorfozom i transformacjom, jednak ich ewolucja nie ma charakteru linearnego, lecz podlega zasadzie redundancji ${ }^{35}$ i repartycji ${ }^{36}$,

${ }^{30}$ G. Durand, Les Structures anthropologiques de l'imaginaire, Dunod, Paris 1992, s. VII.

${ }^{31}$ Por. idem, Le Grand Changement ou l'après-Bachelard, „Cahiers de l'Imaginaire" 1987, nr 1.

${ }^{32}$ Idem, Les Structures anthropologiques de l'imaginaire, op. cit., s. 40; G. Durand, C. Sun, Mythe, thèmes et variations, Desclée de Brouwer, Paris 2000, s. 124. Konwergencja (łac. 'upodobnić się') - termin wywodzący się z nauk przyrodniczych. W antropologii - podobieństwo wytworów kulturowych powstałych niezależnie od siebie w różnych kręgach kulturowych.

${ }^{33}$ G. Durand, Figures mythiques et visages de l'œuvre. De la mythocritique à la mythanalyse, Berg International, Paris 1979, s. 316.

${ }^{34}$ Ibidem, s. 40-51.

${ }^{35}$ Redundancja (łac. redundantia - 'nadmiar') - nadmiar znaczenia, nadwyżka semantyczna.

${ }^{36}$ Repartycja (łac. repartitio) - 'rozdział, podział'. 
dzięki czemu możliwe jest odrodzenie figur mitycznych i figur wyobrażeniowych na poziomie innej kulturowej reprezentacji ${ }^{37}$.

Postulaty badawcze Duranda realizują kontynuatorzy jego metodologii, organizując regularnie konferencje na Uniwersytecie w Grenoble: w 2004 roku odbyła się międzynarodowa konferencja Errance et déambulation poświęcona wyobrażeniom błądzenia w kulturze, w 2006 roku literaturoznawcy z CRI wraz z socjologami z Uniwersytetu Pierre Mendès-France zorganizowali sesję naukową na temat kulturowych reprezentacji ciała (Corps, conte et imaginaire), w latach 2006-2008 realizowany był projekt badawczy dedykowany wyobrażeniom ciała w kulturze, którego zwieńczeniem była międzynarodowa konferencja zatytułowana $\mathrm{Du}$ corps enchanté au corps en chantier ${ }^{38}$, w roku 2009 odbyła się konferencja podejmująca zagadnienie inżynierii ciała i kulturowych wyobrażeń ciała ludzkiego jako maszyny-automatu (La Fabrique du corps humain), a w roku 2011 konferencja poświęcona wyobrażeniom choroby w kulturze (La contamination: lieux symboliques et espaces imaginaires).

W ostatnich latach literaturoznawcze badania nad mitem coraz częściej stają się przedmiotem zainteresowania także polskiego środowiska naukowego ${ }^{39}$. W Polsce Durandowska metodologia oraz

${ }^{37}$ G. Durand, Figures mythiques et visages de l'œuvre. De la mythocritique à la mythanalyse, op. cit., s. 58 .

${ }^{38}$ Efekt publikacyjny konferencji stanowi książka: Les Imaginaires $d u$ corps en mutation: du corps enchanté au corps en chantier, red. C. Finz, L'Harmattan, Paris 2008.

${ }^{39} \mathrm{Na}$ uwagę zasługują inicjatywy naukowe podejmowane we współpracy z innymi badaczami przez Marię Cieślę-Korytowską (Oblicza Narcyza: obecność autora $w$ dziele, red. M. Cieśla-Korytowska, I. Puchalska, M. Siwiec, Kraków 2008; Persefona, czyli dwie strony rzeczywistości, red. M. Cieśla-Korytowska, M. Sokalska, Kraków 2010; Prace Herkulesa. Człowiek wobec wyzwań, prób i przeciwności, red. M.Cieśla-Korytowska, O. Płaszczewska, Kraków 2012) oraz Lidię Wiśniewską (Mity, mitologie, mityzacje - nie tylko w literaturze, red. L. Wiśniewska, Bydgoszcz 2005; Literackie drogi wobec mitu, red. L. Wiśniewska przy współpracy M. Gołuńskiego, Bydgoszcz 2006; Mity słowa, mity ciała, red. L. Wiśniewska, M. Gołuński 
postdurandowska hermeneutyka tekstów literackich pojawiają się już w pracach: romanistów (Barbara Sosień ${ }^{40}$, Stanisław Jasionowicz ${ }^{41}$, Krystyna Falicka ${ }^{42}$, Marcin $\mathrm{Klik}^{43}$ ), teoretyków literatury (Joanna Ślósarska ${ }^{44}$ ) oraz polonistów (Włodzimierz Szturc ${ }^{45}$, Marek Dybizbański $\left.{ }^{46}\right)^{47}$. Z inicjatywy Barbary Sosień w 1995 roku powstał w Instytucie Filologii Romańskiej Uniwersytetu Jagiellońskiego interdyscyplinarny Zespół do Badań Wyobraźniowości Symbolicznej ${ }^{48}$ (E.R.I.S. - Equipe de Recherche sur l'Imaginaire Symbolique),

przy współpracy A. Stempki, Bydgoszcz 2007; Tożsamości i rozdwojenie w perspektywie mitu, red. L. Wiśniewska, Bydgoszcz 2008; Przemiany mitów i wartości - nie tylko w literaturze, red. L. Wiśniewska, M. Gołuński, Bydgoszcz 2010; Beatrycze $i$ inne. Mity $w$ literaturze $i$ kulturze, red. G. Borkowska, L. Wiśniewska, Gdańsk 2010; Don Kichot i inni. Postacie mityczne w perspektywie komparatystycznej, red. L. Wiśniewska, Bydgoszcz 2012).

${ }^{40}$ Por. B. Sosień Images, symboles, mythes et poétique de l'ascension, Kraków 2007; eadem, Imaginer le jardin, Kraków 2003; Intertekstualność i wyobraźniowość, red. B. Sosień, Kraków 2003.

${ }^{41}$ Por. S. Jasionowicz, Roland Barthes - Gilbert Durand. Wizje pluralizmu kultury, Kraków 1999.

42 Por. Potęga świata wyobrażeń, czyli archetypologia według Gilberta Duranda, red. K. Falicka, Lublin 2002.

${ }^{43}$ Koordynator projektu realizowanego w latach 2013-2014 w Instytucie Romanistyki Uniwersytetu Warszawskiego, którego efektem publikacyjnym jest monografia Palingeneza mitu w literaturze XX i XXI wieku, red. M. Klik, J. Zych, Wydawnictwo Uniwersytetu Warszawskiego, Warszawa 2014.

${ }^{44}$ Por. J. Ślósarska, Badź szybszy od śmierci. Studia z antropologii kultury, Łódź 2009; eadem, Studia z poetyki antropologicznej, Warszawa 2004; eadem, Mistyczne i archetypiczne obrazy kosmosu, Warszawa 1994; eadem, W świetle symboli, Łódź 1994.

${ }^{45}$ Por. W. Szturc, Archeologia wyobraźni. Studia o Słowackim i Norwidzie, Kraków 2001; idem, „Faust” Goethego. Ku antropologii romantycznej, Kraków 1997.

${ }^{46}$ Por. M. Dybizbański, W. Szturc, Mitoznawstwo porównawcze, Kraków 2006.

47 W roku 2011 z inicjatywy neofilologów z Wydziału Filologicznego Uniwersytetu Jagiellońskiego odbyła się w Krakowie interdyscyplinarna konferencja Horyzonty wyobraźni. Pracownia Mitopoetyki i Filozofii Literatury Instytutu Filologii Polskiej Uniwersytetu Zielonogórskiego w 2010 roku zorganizowała konferencję naukową poświęconą tematyce zogniskowanej wokół problematyki: Mit - Literatura.

${ }^{48}$ Barbara Sosień francuski termin imaginaire na język polski tłumaczy jako 'wyobraźniowość', por. B. Sosień, Intertekstualność i wyobraźniowość, op. cit., s. 5. 
prowadzący badania inspirowane metodologią Durandowską. W roku 2014 w Uniwersytecie Łódzkim w Instytucie Filologii Polskiej rozpoczęło swoją działalność studencko-doktoranckie Koło Naukowe Mitokrytyków, którego celem jest propagowanie i rozwijanie mitokrytycznych badań nad tekstem literackim. Wszystkie te inicjatywy, jednoczące środowiska naukowe, dają świadectwo ekspansji coraz dynamiczniej rozwijającego się w światowej nauce postdurandowskiego nurtu badań ${ }^{49}$, w którym mit zajmuje miejsce wyjątkowo ważne.

\section{Bibliografia}

Brunel P., Mythocritique, théorie et parcours, PUF, Paris 1992.

Brunel P., Mythopoétique des genres, PUF, Paris 2003.

Chauvin D., La Bible, images, mythes et traditions, Albin Michel, Paris 1994.

Durand G., Figures mythiques et visages de l'oeuvre. De la mythocritique à la mythanalyse, Berg International, Paris 1979.

Durand G., Les Structures anthropologiques de l'imaginaire, Dunod, Paris 1992.

Durand G., Sun C., Mythe, thèmes et variations, Desclée de Brouwer, Paris 2000.

Dybizbański M., Szturc W., Mitoznawstwo porównawcze, Kraków 2006.

Les Imaginaires du corps en mutation: du corps enchanté au corps en chantier, red.

C. Finz, L'Harmattan, Paris 2008.

Intertekstualność $i$ wyobraźniowość, red. B. Sosień, Kraków 2003.

Jasionowicz S., Roland Barthes - Gilbert Durand, wizje pluralizmu kultury, Kraków 1999.

Karwowska M., Antropologia wyobraźni twórczej w badaniach literackich. Świat wyobrażony Brunona Schulza, Łódź 2015.

Karwowska M., Prapamięć uśpiona. Świat wyobrażeń Bolesława Leśmiana, Warszawa 2008.

Lectures politiques des mythes littéraires au $\mathrm{XX}^{e}$ siècle, red. S. Parizet, Presses Universitaires de Paris Ouest, Paris 2009.

Lévi-Strauss C., Antropologia strukturalna, przeł. K. Pomian, Warszawa 1970.

Monneyron F., Thomas J., Mythes et littérature, PUF, Paris 2002.

Mythes et littérature, red. P. Brunel, Presses de l' Université de Paris-Sorbonne, Paris 1994.

Mythes et littérature, red. S. Parizet, Lucie éditions pour la SFLGC, Paris 2008.

${ }^{49}$ Szerzej na ten temat por. M. Karwowska, Antropologia wyobraźni twórczej w badaniach literackich. Świat wyobrażony Brunona Schulza, Łódź 2015, s. 55-81. 
Le Mythe en littérature. Mélanges offerts à Pierre Brunel, red. C. Dumoulié, Y. Chevrel, PUF, Paris 2000.

Mythe et création, red. P. Cazier, Presses Universitaires de Lille, Lille 1994.

Oblicza Narcyza: obecność autora w dziele, red. M. Cieśla-Korytowska, I. Puchalska, M. Siwiec, Kraków 2008.

Palingeneza mitu w literaturze XX i XXI wieku, red. M. Klik, J. Zych, Warszawa 2014.

Persefona, czyli dwie strony rzeczywistości, red. M. Cieśla-Korytowska, M. Sokalska, Kraków 2010.

Potęga świata wyobrażen, czyli archetypologia wedtug Gilberta Duranda, red. K. Falicka, Lublin 2002.

Prace Herkulesa. Człowiek wobec wyzwań, prób i przeciwności, red. M. CieślaKorytowska, O. Płaszczewska, Kraków 2012.

Questions de mythocritique. Dictionnaire, red. D. Chauvin, A. Siganos, Ph. Walter, Imago, Paris 2005.

Les Représentations de la Terre dans la littérature et l'art européens. Imaginaire et Idéologie. Actes du colloque des 18-19-20 mars 2004 en Sorbonne, red. D. Chauvin, D. Knysz-Tomaszewska, „Les Nouveaux Cahiers Franco-Polonais" 2005, nr 4.

Sosień B., Images, symboles, mythes et poétique de l'ascension, Kraków 2007.

Sosień B., Imaginer le jardin, Kraków 2003.

Szturc W., Archeologia wyobraźni. Studia o Słowackim i Norwidzie, Kraków 2001.

Ślósarska J., Badź szybszy od śmierci. Studia z antropologii kultury, Łódź 2009.

Ślósarska J., Studia z poetyki antropologicznej, Warszawa 2004.

Vierne S., Rite, roman, initiation, Persses Universitaires de Grenoble, Grenoble 2000.

Walter Ph., La Mythologie chrétienne, fêtes, rites et mythes du Moyen Age, Imago, Paris 2003. 